\title{
"Breaking the Glass": When Woman Became a Leader in an Indonesian State University
}

\author{
Rabina Yunus ${ }^{1}$, Sukri $^{2}$ \\ (rabina_yunus@yahoo.com ${ }^{1}$, sukripolitik@gmail.com²) \\ Faculty of Social and Political Science, Hasanuddin University \\ Jl. Perintis Kemerdekaan Km. 10, Makassar, Indonesia
}

\begin{abstract}
This paper aims to show how the gender difference has been seen as a natural barrier for women, including access to some important positions in the equal work. By looking at phenomenon of women elected as University rector at the one of best university in Indonesia, this paper wants to show how it basically as an answer to tendency of mistakes in stereotyping women based on culture perspectives over the years. The recently tendency shows how women are considered as weak person and does not have ability to be a leader compared with male. It seems became a cultural barrier that tightly binding women that put women in the glass ceiling condition that seems have been transformed as a natural necessity and justification to undermines chances and opportunities. It means, effort to promote gender equality is important not only as a discourse but as a collective consciousness and actions. In the end, the gender difference is not actually as absolute and natural obstacle of women to compete equally with men in various fields. It should be seen as part of potential typical obstacles for women as well as men that also have their potential barriers too.
\end{abstract}

Keywords : Gender Equality, Glass Ceiling, Cultural Tightness, Leadership, University

\section{Introduction}

The gender inequality issue between women and men in social, political, and economically is still one of the important issues of many countries in the world [1]. Today, although women have more roles in various processes of society development than ever before, but it seems some obstacles and barriers still obstruct women participation in compare with men. In some regions of the world, large number of women remains isolated, disorganized, poor, and limited by the structure of the socio-cultural that restrict their abilities to have access or be involved to access some important positions as decision makers in variety of work environment [2].

That condition seems could not inseparable from historical experiences, which shows the concept of labor division, men have always been considered as the most appropriate to lead [3]. Although there are number of women that become a successful leader and have great influence in public life, but it seems that it is still not seen as equal achievement to men side. The women's leadership phenomenon tends only to be seen as a coincidence due to the leadership is seen as male domain [4]. It seems to be associated to have presumption that women are weak.

In Indonesian context, the gender difference seems to not only consider as causes of leadership style difference of women and men. It is also seen as basic view to women inappropriate due to the natural sex different. It seems made successful woman as leader in best university will be seen more like as coincidence. If it is not then the success of women will be seen as result of involvement of some remarkable things that impose the university system to 
accept women. It certainly raises big questions of how women can be seen in that situation and do they deeply could not be a success leader in terms of culture context. Basically, this condition should not arise due to Indonesian constitution that regulates equal rights for all people. But the culture reasons. It means cultural aspect is influencing in perception of women and men equality based on their differences in sex aspect. The natural difference in sex aspect is also considered as natural condition of women's weakness where men as the stronger one that confirmed as right think under the cultural perspective. It tends underlying the assumption that only men will be successful as leader. Women are generally considered to have weakness that will affect their leadership models therefore potentially it will fail when she occupied a high level position in an institution including a higher education institution.

\section{Research Method}

This paper is based on the results of research conducted in the Makassar, especially in the Hasanuddin University. Based on the qualitative study emphasizing in the case studies, with interview and a few document analysis, this study intends to show how women succesfully proof her ability to be a lader in prominent high education institute which strongly dominated by Men in quantitative.

\section{Results/preliminary result/critical review}

The goal to put women as equal as men in various dynamics of social life is mainly associated with recognition of the human rights [5]. It means basically there is no reason to distinguish women and men rights to participate, including access to various important positions in an institution. Women are also as important part of the social life as well as men [6]. But nonetheless, it is still overshadowed by a condition that inhibits women inferiorly due to their sex difference.

Basically that difference is only a biological natural aspect, but it seems to be associated to women's physical weakness so they will be more suitable for domestic work. It means they are presumed to not be able to handle various works that will interact externally with more people and complicated problems. As for men, due to they are presumed as stronger then they are appropriate to work outside that is considered to the need of a stronger figure that only belongs to men. That condition actually is a residual effect of labor division in the humankind history between women and men. Men are considered as bigger and able to better build, hunt, and protect their families, whereas women are seen to be weaker. Due to that condition has been part of humankind life for hundred or even thousand years, so it seems to still influence even though some scientific and technological development have much alleviate the pressure on the gender difference [7]. When that condition is likely to be accepted as part of social dynamics itself, it then becomes social culture that put women in glass ceiling that hold up women tightly but it seem does not appear.

Institutionally, related to chances to access some important positions or become a leader in an organization, women and men are not restricted by the gender difference. It is because when people want to find a leader, they are actually looking for someone who can provide directions, make big decisions, and inspire to achieve some desired goal or achieve what was previously unattainable. In this point, women and men basically have same opportunity to fulfil it. The 
important thing for an organization is not a gender based on leadership but the leader's capability to running this organization well. It means ideally the gender differences should not be the main reason. But in reality, some trends keep showing that the difference becomes crucial factor. That condition indicates that the context of the gender difference is seen as common dynamics in social life [8]. Gender difference seems to be considered to contain certain decencies that provide more opportunities to men than women. In this view, women have impropriety due to their limitations as the consequences of gender difference.

That condition indicates organizational culture tends to bias masculinity that gives more opportunity for men due to more appropriate than women. It puts women in disadvantageous position in competing to be leaders [9]. One important thing to explain such condition is closely associated to the cultural factors [10].

As culture tends to be regarded as important norm in the social life then it makes gender differences as a fundamental part in seeing how men and women should carry their roles. Cultural perspectives seem to become crucial standard in assessing whether women are worthy or not being a leader. As culture existence is seen as like as norm that require adherence, then it seems like the ideal thing of leadership. It means, obedience consider as good behave while violation will be seen as negative attitudes. It then narrows opportunities for women while it provides privilege for men [11].

That condition seems to ignore many women's achievements, even if they have been women occupy important position or even as a leader of an institution. Existence of various antidiscrimination regulations, equality of opportunity, and affirmative action provide more opportunity, but the gender equality does not exist properly. Due to culture is part of daily social life then makes it able to be felt but seems to not exist clearly to restrict women as invisible obstacle. Women are seemed to be in a glass room that is not clearly seen but has strong limitations where it is commonly known as the glass ceiling [12].

Basically the glass ceiling metaphor is just to help explaining why the number of women is very small in the leadership and decision-making positions. As one part significance barriers, cultural aspect is not visible but it has real effect in inhibiting women due to gender differences with men [13]. It makes culture to become the glass ceiling for women. In the context of men bias culture, glass ceiling deeply puts women as domestic workers in the system of division of labor [14] where men as the external worker, including as the leader, should have good ability to build relationship with various people.

In this context, male seen as the most suitable to lead and women must accept it as natural condition as part of adherences to the culture. As its effect, women in an organization or institution inclined to be not visible. It is not only because their little in number but also ignored for some important roles. As condition that exists continuously, cultural barriers then encourage a particular stereotype for women as incapable [15]. It seems to be related with basic assumption that women have natural obstacles that make them weak. Therefore, it seems people will easier to accept a man than women as a leader.

Nowadays, it seems that cultural reason seems still lay the women and men in unequal separation. Consequently, a leader woman tends to see it as social deviation. This view actually seems to ignore women's potential and ability that may be similar or even better than men. In this view, the gender difference for women seems to become a curse that prevents them to occupy same position or even better than the men's achievement [16]. Furthermore, if a woman becomes a leader then they will be seen only as an attempt to imitate what men do. That condition shows that only men who can be the best patron to formulate concept of the success leader. In this position, women may have formal rights based on some regulations, but in cultural 
context where sometimes it is not realized that women impede to stand in equal position with man.

Existence of a culture is seen as part of social norm as driving factors of society perspectives in gender difference [17]. It leads strong obstacles that produce perspectives consistency of people related to leadership and the deserved leader [18]. As results, there will always be reason to see leadership as men domain where women are inappropriate. In this situation, even women have good performance or even more then men have, it will be seen as result of imitate effort of women to men's ability.

It assume that women are difficult to compete with men where at the same time men will more success than women. That condition appears hampered women's opportunities even they possibly have equality. Even assumption that sees female leadership always brings gender issues along their leadership is not actually something that proves women weakness or women potential threats the institution [19]. Therefore, basically the difference of men and women in sex context should not be a reason to consider their inequality.

\subsection{Women and the Gender Equality in the Indonesian Higher Education Institution}

In the higher education fields, both in teaching and managerial positions, women seem still far from equal not only in term of quantity but also in occupying some important positions. While women have made some progress in achieving parity in teaching but they tend to be under-represented the high management positions [20]. It seems it is still associated with assumption that women have natural inability that makes them weak in compare with men. Basically various phenomena, including in higher education institutions, indicate that women have made significant progress in access to important positions. Yet despite that it seems there are barriers that prevent academician women to be able to increase their competence and to gain important positions in the institution [21].

Basically there are not many evidence can be stated that women are indeed difficult to compete with men, including being leader or policy makers, that prove lack of women capacity. However, the gender difference seem still remain as obstacle associated with culture. It makes even some women to have ability and be appropriate to the professional qualification similar as men, but their position will still be considered behind men. The cultural factors seem as strong separator due to gender stereotype that make women seem as unprofessional in this difference. In the context of high educational institutions such as universities, it should not happen.

University's position as an institution is built on respect for science and rationality is essentially a guarantee of equality of gender. It is including access to leadership positions. But it seems that it is still in tendency of being influenced by important factor of culture in assessing the propriety of a leader that is male bias, including in Indonesia. In this condition, it seems as a surprise when a university in Indonesia especially one of the best universities in Indonesia is led by woman rector. This fact seems trigger contrary views of women where they usually considered as the weaker.

As important educational institution in Indonesia, universities runs by people who have excellent educational and good ability in leadership background. As the aim is to educate people, university is important institution to produce intelligent and rational people without differentiating gender background. Its importance position then makes university should have good management to handle all of its goals. It means university needs appropriate people in management position including the highest leader. Due to its complexity dynamics in management where it should harmonize some tasks, regulation and people then make the university's leader in Indonesia must be a person who is internally acceptable and able to interact 
externally with various related parties. Therefore, the rector should be a person who has good ability and appropriate to all formal requirements.

As a prominent higher education institution, a university is built on respect for science and rationality is essentially a guarantee of equality of gender. It is including access to leadership positions. But it seems that it is still in tendency of being influenced by important factor of culture in assessing the propriety of a leader that is male bias, including in Indonesia. In this condition, it seems as a surprise when a university in Indonesia especially one of the best universities in Indonesia is led by woman rector. This fact seems trigger contrary views of women where they usually considered as the weaker. As the one of prominent University in Indonesia, the Hasanuddin University experiencing an interesting phenomenon related to issue about the Woman Leader. In the first time, this university leads as rector by a woman who voted thru democratic process that was dominated by men voters.

Hasanuddin University was founded in 1956. It is one of influential universities in Indonesia. Its position became interesting due to the university is the only university outside of the Java Island as prominent university. Based on the history of this university the recent rector is the first rector ever. Since 1956 this university was leads by 12 rectors where 11 of it were men. It shows how women actually could lead this important education institution where previously dominated by men. Actually, in the formal term, this phenomenon is not an extraordinary thing since there is no difference in rights for women or men in opportunity to get it based on the constitution. But due to that position is in institutions where quantitatively dominated by men and the process is complicated to win then make this seems as a amazing phenomena. Based on data in in 2017, Hasanuddin University has 1617 lectures where 1006 lectures are Men and only 611 are Women. Within that numbers only 86 lectures as the university senators who have rights to vote for the rector. Among the number of senators, only 17 of it is Women and 69 are Men. That condition shows difficulty to win the position due to candidate should have majority support of voters. They must fulfill not only the standard of professional quality (good capacity and capability) but also should accepted by majority voters where separately based on faculty and department. Under the tendency of cultural view that Men usually appropriate for a highly leader position then made a woman will difficult to win the position. Therefore, when women who successfully win the position as top leader of best university in Indonesia, actually was not as a coincidence or affirmation results. It is actually a result of women's effort and capability to meet all requirements, including winning men votes from various parties.

That fact actually deeply confirmed that the voters believe that the she has good ability and quality to lead the university and for this time even more than all men candidates. The cultural tightness' conditions that formed glass ceiling seen not as an obstacle factor, but as challenge to prove her capacity in comparison with men candidates. If that condition has become a bottleneck, then success of women to occupy some important position, such as the top of university, basically is a fact that they have appropriate ability. Moreover, they have demonstrated an exceptional condition to go through the culture's confinement as result of effort to emerge from cultural stereotyping pressures [22] .

It means, the glass was cover woman to be a proper leader has been broke. The new rector has successfully shows her quality and for generally proof that women actually have quality and capability to be a leader when they have chance for it. Moreover, her achievement has break the general tendency of the women leader where usually seen as weaker than men. Her successfully to win absolute majority in the voting day actually confirm that She is a high quality leader and has been proof it thru her works where bring her as the leader for the second period. It means She has succeed to broke the Glass ceiling where usually trap women in the restricted access condition. 


\section{Conclusions}

The gender difference indeed has been one obstacle for women to be able to occupy some important positions in various important institutions in comparison to men. It is one of the cultural tendencies that onset of women stereotyping as weak people and do not have appropriate ability. It seems to be influenced by trends of the division of labor system between men and women that put women at the domestic side as the natural condition. It makes women seem to not have enough space to out and compete with men equally. It shows how the culture tightness has formed glass ceiling that covers women's life and creates fundamental challenges for women. Women seem to have double challenges in the process to compete to men. Besides to meet the formal requirements, they should also be able to prove their ability to show that stereotyping against them is unproved and unfair.

Success of woman as leader of important institutions such as university in Indonesia is primarily a concrete fact that women are able to win the competition. That phenomenon is not coincidence or result of affirmative action, it is not only seen as women's ability to meet the formal requirements but also as proof to the cultural tendency that seems to see women as the weaker gender.

Finally, despite the cultural inclination to distinguish women and men in leadership discourse still happens, but it is not a condition that should be mourned by women. That condition can be aspect that possibly encourages women to strive much harder than men. Therefore the success of women to occupy important position will be seen as successful effort in solving the glass ceiling problem that is not experienced by men. The success of women possibly will have more great impact to prove the fallacy of general views in them as the natural weaker gender compared to men.

\section{References}

[1] United Nations.: Achieving Gender Equality, Women's Empowerment and Strengthening Development Cooperation. Department of Economic and Social Affairs Office for ECOSOC Support and Coordination. United Nations. New York (2010)

[2] Mokate, Karen (ed.):: Women's Participation in Social Development : Experiences From Asia, Latin America and the Carribean. Inter-American Development Bank. Washington, (2004)

[3] Kiamba, Josephine M.: Women and Leadership Positions: Social and Cultural Barriers to Success. Wagadu Volume 6 Winter.pp. 7-26 (2008)

[4] Højgaard, L.: Tracing differentiation in gendered leadership: An analysis of differences in gender composition in top management in business, politics and the civil service. Gender, Work \& Organization, Vol.9.pp. 15-38 (2002)

[5] United Nations.: Women's Rights are Human Rights. United Nations Publication (2014)

[6] Mokate, Karen (ed.).: Women's Participation in Social Development Experiences From Asia, Latin America and the Carribean. Inter-American Development Bank. Washington (2004)

[7] Parcheta, Nicole, Xtreme Trips HS, Belal A. Kaifi, Nile M. Khanfar.: Gender Inequality in the Workforce A Human Resource Management Quandary. Journal of Business Studies Quarterly. Vol 4.pp. 240-248 (2013)

[8] FAO.: Agricultural Censuses and Gender Considerations - Concept and Methodology, (2001)

[9] Eagly, Alice H. Achieving relational authenticity in leadership: Does gender matter The Leadership Quarterly Vol.16.pp. 459-474 (2005)

[10] Toh, Soo Min and Geoffrey J. Leonardelli.: Cultural constraints on the emergence of women as leaders. Journal of World Business Vol.549.pp.1-8 (2012) 
[11] Toh, Soo Min and Geoffrey J. Leonardelli.: Cultural constraints on the emergence of women as leaders. Journal of World Business Vol. 549.pp.1-8 (2012)

[12] Toh Weyer, Birgit.: Twenty years later: explaining the persistence of the glass ceiling for women leaders. Women in Management Review, Vol. 22 .pp. 482-496 (2007)

[13] Barreto, M., Ryan, M., \& Schmitt, M.: The glass ceiling in the 21st century: understanding barriers to gender equality. Washington: American Psychological Association (2009)

[14] Glass Ceiling Commission (2003)

[15] Eaglya, Alice H. and Linda L. Carlib.: The female leadership advantage: An evaluation of the evidence. The Leadership Quarterly Vol.14.pp. 807-834 (2003)

[16] Mokate, Karen (ed.).: Women's Participation in Social Development : Experiences From Asia, Latin America and the Carribean. Inter-American Development Bank. Washington (2004)

[17] Gelfand, M. J., Nishii, L. H., \& Raver, J. L.: On the nature and importance of cultural tightness looseness. Journal of Applied Psychology. pp. 1225-1244 (2006)

[18] Toh, Soo Min and Geoffrey J. Leonardelli.: Cultural constraints on the emergence of women as leaders. Journal of World Business 549; No.of Pages.pp.1-8.(2002)

[19] Cornwall, Andrea: Whose Voices? Whose Choices? Reflections on Gender and Participatory Development. World Development Vol. 31.pp.1325-1342 (2003)

[20] Cornwall United Nations Educational, Scientific and Cultural Organization.: Women and management in higher education. A good practice Handbook. Follow-up to the World Conference on Higher Education. Paris, (1998)

[21] Okpara, John O., Michael Squillace, and Emmanuel A. Erondu.: Gender differences and job satisfaction: a study of university teachers in the United States", Women in Management Review, Vol. 20.pp. 177-190 (2005)

[22] Okpara Catalyst.: The Double-Bind Dilemma for Women in Leadership: Damned if You Do, Doomed if You Don't. New York (2007) 